\title{
The natural history of HIV infection in women attending a sexually transmitted disease clinic in Dublin
}

F Mulcahy, G Kelly, M Tynan

\begin{abstract}
Objective-To determine the progression rates to AIDS in women in Dublin.

Subjects and methods-109 HIV-1 seropositive women who presented to the Department of Genitourinary Medicine, St. James's Hospital, Dublin, were included in a retrospective analysis. Of these 101 (93\%) were intravenous drug users (IVDUs), 7 were heterosexual partners of IVDUs and one had a heterosexual partner of no known risk group. Forty-four women (40\%) had had 57 children since the time of their first known HIV seropositive test. Progression rates from CDC Stage 11/111 to AIDS are computed. Progression curves are generated according to the Kaplan-Meier method using the Statistical Analysis Software (SAS).

Results-The estimated cumulative progression rate at 5 years was $24 \%$ (SE $6.6 \%)$. 17 out of $109(15 \cdot 6 \%)$ developed AIDS. The mean follow up time was $2 \cdot 8$ years (SE 0.2). The prevalence of oesophageal candidiasis taking development of AIDS as the point in time was 9 out of 17 (53\%), of Mycobacterium hominis infection (TB) $5(29 \%)$ and of Pneumocystis carcinii pneumonia (PCP) $2(12 \%)$. There was no statistical difference in progression rates to AIDS between those women who had children after becoming infected versus those who had none.

Conclusions-Progression rates to AIDS in Irish women is higher than reported in other studies of homosexual/bisexual men, but is similar to rates estimated for both male and female IVDUs. Oesophageal candidiasis is the commonest presenting AIDS diagnosis followed by TB, while PCP is rare, contrary to the findings of similar studies in the USA.
\end{abstract}

Medicine Clinic, St.

James Hospital, James's Street PO Box 580

Dublin-8

F Mulcahy

M Tynan

Department of

Statistics, University

College Dublin

G Kelly

Address correspondence to: Dr F Mulcahy

Accepted for publication 12 November 1993

\section{(Genitourin Med 1994;70:81-83)}

\section{Introduction}

The acquired immunodeficiency syndrome (AIDS) epidemic has grown slowly in Ireland. The first reported case was in a homosexual man in 1982 and there were a total of 258 cases in the Republic by the end of $1991 .^{1}$ However, by November 1991, 1146 individuals in Ireland had tested positive for the HIV antibody, $150(13 \cdot 1 \%)$ of whom were female. Most of these women are intravenous drug users (IVDU). The proportion of AIDS cases arising from the IVDU risk group has risen steadily from $30 \%$ at the end of 1987 to $37 \%$ at the end of 1991 and with it the proportion of AIDS cases among women. A similar increase in the incidence of AIDS in women has been reported in other countries, in particular the USA..$^{2-3}$ Therefore it is of increasing importance to examine the natural history of HIV infection in women. Here we outline the details of such a study. The majority of Irish HIV cases are centred in the Dublin area and 109 HIV positive Irish women have attended the Genitourinary clinic in St. James's Hospital, Dublin. A retrospective analysis of HIV positive female admissions to the clinic for the period January 1987 to January 1991 was conducted.

Progression rates to any Center for Disease Control (CDC) group IV disease and to AIDS for these women are presented. Possible effect of pregnancy during the course of HIV infection on progression rates is explored. Progression rates for women who do not have babies during the course of their HIV infection are compared with those for women who do. We also compare our progression rates with those of homosexual cohort studies and with other cohort studies of IVDU's compiled from the literature.

\section{Patients and methods}

A total of 109 women who presented at the Dublin sexually transmitted disease clinic between January 1987 and January 1990 were anti-HIV-1 seropositive. They were followed to 1 February 1991. The dates of their first positive HIV test ranged from 15 January, 1983 to 30 September, 1990, the median date being 15 June, 1987 . The CDC classification of $1987^{4}$ for the manifestation of HIV infection was used to classify patients. The major transmission category was IV drug usage. Of the 109 women, 101 (93\%) were IV drug users, seven were heterosexual partners of IV drug users $(6 \cdot 4 \%)$ and one had a heterosexual partner of no known risk group. Six of the 101 IV drug users were prostitutes. At the time of study, 74 of the $101(73 \%)$ were ex IVDUs of whom 54 (53\%) were on methadone. Twenty-seven were current users $(27 \%), 16$ of whom were on methadone. Seventeen patients received anti-retroviral therapy, 14 after an AIDS diagnosis. CD4 cell counts were not available on a routine basis so PCP prophylaxis was 
not initiated unless the patient had reached CDC Stage IV diagnosis.

Forty-four ( $40 \%)$ of the women had had children, since the time of their first known HIV positive test. A total of 57 children were born, nine women had two children, two had three and the remaining 33 had a single pregnancy since seroconversion.

Progression rates from CDC stages II and III to AIDS were computed. All progression curves were generated according to the Kaplan-Meier method using the Statistical Analysis Software (SAS). For each patient the date of first known HIV-seropositive result was the starting point on the follow-up scale. The exception to this were seven patients for whom an HIV-seronegative date was available. For these seven, the starting point was taken as the date midway between the last known negative and first known positive tests for anti-HIV. In computing progression rates to AIDS all 109 patients were included in the risk set. The number of days of follow-up was taken to the date at which the patient developed an AIDS illness or the date of last visit

Table 1 Distribution of first AIDS-defining events

\begin{tabular}{ll}
\hline & Number \\
\hline Oesophageal candidiasis & 6 \\
Mycobacteria hominis infection & 5 \\
PCP & 1 \\
Specific neurological disease & 0 \\
Other (CDC 4C1) & 2 \\
Oesophageal candidiasis and PCP & 1 \\
Oesophageal candidiasis and TB & 1 \\
Oesophageal candidiasis and other & 1 \\
& 17 \\
\hline
\end{tabular}

Table 2 Cumulative progression rates (standard errors) to $C D C$ stage 4 and to AIDS from date of entry to the study

\begin{tabular}{llll}
\hline Year & No. in follow-up & $\begin{array}{l}\text { Progression rate } \\
(\%)\end{array}$ & (SE) (\%) \\
\hline 1 & 85 & $5 \cdot 7$ & $(2 \cdot 3)$ \\
2 & 64 & $8 \cdot 4$ & $(2 \cdot 9)$ \\
3 & 51 & $11 \cdot 6$ & $(3 \cdot 6)$ \\
4 & 38 & $11 \cdot 6$ & $(3 \cdot 6)$ \\
5 & 12 & $24 \cdot 0$ & $(6 \cdot 6)$ \\
6 & 5 & $36 \cdot 7$ & $(12 \cdot 8)$ \\
\hline
\end{tabular}

Number of subjects who progressed: 17 out of 109 (15.6\%) Mean follow-up time: $2 \cdot 8$ years (SE $0 \cdot 2$ ).

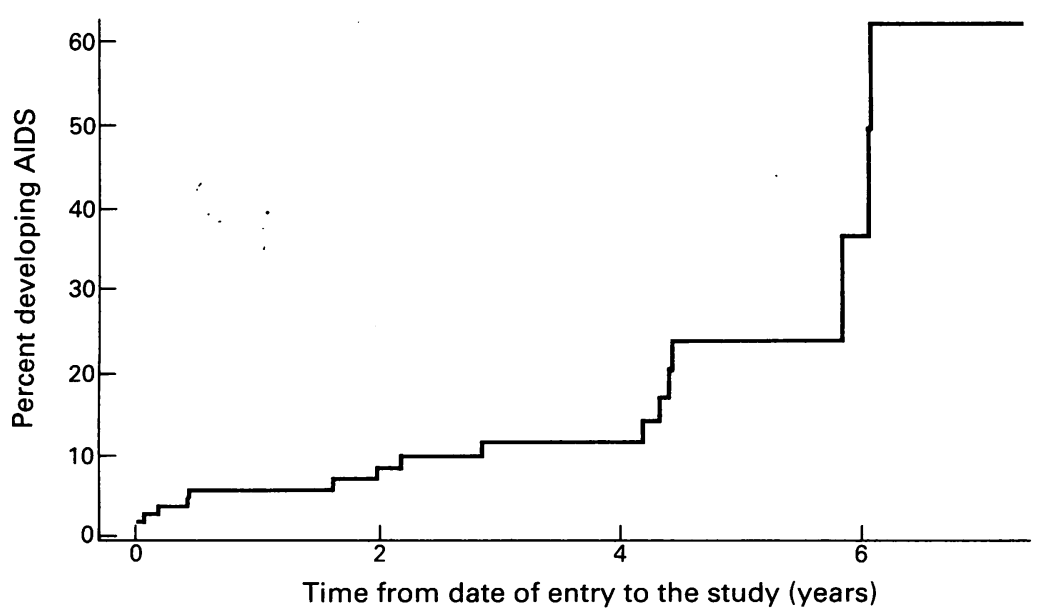

Kaplan-Meier progression rates to AIDS for 109 HIV seropositive women. at the clinic at which the patient was asymptomatic, before 1 February 1991.

\section{Results}

The average age at entry to the study was 25.6 years with a standard error of 0.5 years. The ages ranged from 19 to 41 . At study entry, 100 of the women were in CDC stage II and 7 were in stage III. Two presented with AIDS. Twenty-one of the 109 (19.3\%) progressed to some stage IV disease of whom six had CDC stage IV C2 (ARC) as their first diagnosis and 15 had an AIDS diagnosis. Of the six who did not have AIDS as the first diagnosis, two subsequently went on to develop AIDS. This gave a total of 17 of 109 $(15.6 \%)$ who developed AIDS in this group of women. In all of these cases opportunistic infection was the first CDC stage IV presentation (table 1). If the development of AIDS is taken as the point in time then the prevalence for oesophageal candidiasis is $53 \%$, for TB is $35 \%$ and for PCP is $12 \%$. The incidence of opportunistic infections changed over time. For oesophageal candidiasis there was one in 1987 , one in 1988 , two in 1989 and seven in 1990

The progression rates to AIDS and the associated standard errors, together with the sample sizes on which the estimates are based are shown in table 2 . The progression rate to AIDS at 4 years is $12 \%$ and at 5 years is $24 \%$ (fig 1).

All the women were of child-bearing age and $44(40 \%)$ of them had children after becoming infected. Eight $(18 \%)$ of women who had babies progressed to AIDS and the rate was $14 \%$ for women who did not have babies. The Kaplan-Meier progression curves to AIDS for the two groups were not significantly different. Likewise there was no statistical difference in progression between current IVDUs and ex-IVDUs (Log Rank Test). Moreover, age was not a statistically confounding factor in either of these analyses.

\section{Discussion}

The pattern of AIDS presentation as seen in table 1 is different from that reported in the USA, where the incidence of PCP among infected women is higher and the incidence of oesophageal candidiasis is rare. Guinan $e t a \bar{l}$ in a study of 1819 women with AIDS in the USA reported a $66 \%$ incidence of PCP, similar to males in the USA. In a study at The New York Hospital $^{6}$ of women with AIDS, $57.1 \%$ had PCP as their first opportunistic infection versus $10.7 \%$ with oesophageal candidiasis. By contrast $35 \cdot 3 \%$ had oesophageal candidiasis in this study. However Carpenter $e t a l$ in a study of 200 anti-HIV positive women in Rhode Island reported a similar figure of $34 \%$ with oesophageal candidiasis as an AIDS defining event. This may reflect local disease variations associated with different risk groups or environmental factors. Carpenter et al have also noted that clinical signs of advanced HIV-related immunodeficiency vary around 
Table 3 Cumulative progression rates (\%) to AIDS in studies of IVDU's.

\begin{tabular}{|c|c|c|c|c|c|c|}
\hline & Year: 1 & 2 & 3 & 4 & 5 & 6 \\
\hline $\begin{array}{l}\text { Alcabes et al }{ }^{9}: \text { USA }(\mathrm{n}=343) \\
\text { Jordi et al }{ }^{10}: \text { Spain }(\mathrm{n}=649) \\
\text { Montalla et al }{ }^{11}: \text { Italy }(\mathrm{n}=539) \\
\text { McNeil et } \text { al }^{12}: \text { Edinburgh }(\mathrm{n}=403)\end{array}$ & $9 \cdot 0$ & $5 \cdot 6$ & $\begin{array}{l}11 \cdot 6 \\
11 \cdot 0 \\
26 \cdot 0\end{array}$ & $\begin{array}{l}17 \cdot 6 \\
18 \cdot 0\end{array}$ & $\begin{array}{l}22 \cdot 8 \\
48 \cdot 0 \\
34 \cdot 3\end{array}$ & $29 \cdot 1$ \\
\hline
\end{tabular}

the world, the reasons for which are not fully understood.

Kelly et al (1990) ${ }^{8}$ compiled progression rates to AIDS of six independent cohorts of homosexual and bisexual men. In each study the date of seroconversion of the subjects was either known or estimated. The estimated cumulative rates at five years ranged from $11 \%$ to $23 \%$ with a median of $14 \%$. The corresponding estimate in this study is $24 \%$ (SE $6.6 \%$ ), the highest in comparison. There are two possible explanations for this. Some women may have been HIV positive for a long time before coming to the clinic. The study at The New York Hospital also found that women tend to seek treatment late in their clinical course. Thus they have been infected for longer than their follow-up in this study, and as it is well known that the risk of AIDS for HIV infected persons increases over time, it is possible we have overestimated the progression rates. An alternative explanation is that most of the women are IVDUs and progression rates among IVDUs are higher than in other risk groups because of an already weakened immune system. Table 3 shows cumulative progression rates from four studies of IVDU's, ${ }^{9-12}$ male and female, compiled from the literature. The estimated cumulative rates at five years ranged from $23 \%$ to $48 \%$ with a median of $35 \%$. The corresponding estimate in this study is $24 \%$ showing good agreement. Undoubtedly, progression rates for IVDUs seem to be consistently higher than in the homosexual/bisexual group, suggesting that IVDUs have a poorer prognosis. Currently there is no evidence to suggest that progression rates differ between male and female IVDUs. There is, however, a lot of variability across studies perhaps because of unknown seroconversion dates.

Selwyn et $a l^{13}$ found no adverse effect of pregnancy or HIV progression in a prospective study of 24 seropositive IVDUs. Our data also support this study. This contrasts with earlier studies of HIV, in which HIV disease was found to progress dramatically during or following pregnancy. Lindgren et al ${ }^{14}$ suggest that progression was related to the delivery of an affected baby. Comprehensive data on the HIV status of the children born in our study is incomplete and therefore we cannot comment on this issue at this time.

An increase in AIDS among women from heterosexual partners is a good marker for future trends in the heterosexual population, and is of particular concern. However, the extent to which HIV transmission occurs from the IVDU population to the general heterosexual population is not known. Six percent of women in this study were infected in this manner. Nine percent of AIDS cases in Ireland to December 1991 had occurred in heterosexuals and heterosexuals with no known risk accounted for $11 \%$ of $\mathrm{HIV}$ seropositive cases. Two studies, in the USA ${ }^{15}$ and Italy $^{16}$ have compared progression rates for women in the IVDU and heterosexual risk groups. The US study concluded that women in the IVDU risk group progress more rapidly than women without IVDU history, while the Italian study found the reverse was true. Owing to the small numbers of heterosexuals in this study, it was not possible to compare these groups. Further studies to clarify this important issue are urgently required.

1 Department of Health, Dublin. Quarterly Statistics on AIDS/HIV. 1991.

Campbell C. Women and AIDS. Soc Sci Med 1990;30: 407-15.

3 European Centre for the Epidemiological Monitoring of AIDS. Quarterly Reports on AIDS Surveillance in Europe.

4 Center for Disease Control. Revision of the CDC surveillance case definition for acquires immune deficiency syndrome. $M M W R$ 1987;36(suppl. 15):35-155.

5 Guinan M, Hardy A. Epidemiology of AIDS in women in the United States, 1981 through 1986. $¥ A M A$ 1987; 257:2039-42.

6 LaTrenta L, Jacobs J, Goldstein M. Characteristics of women in a New York City HIV clinic. 8th International Conference on AIDS/3rd STD World Congress, Amsterdam 1992. (Abstract PoC 4728, Vol 2).

7 Carpenter C, Mayer K, Stein M, et al. Human immunodeficiency virus infection in North American women: experience with 200 cases and a review of the literature. Medicine (Baltimore) 1991;70:307-25.

8 Kelly G, Stanley B, Weller D. The natural history of immunodeficiency virus infection: a five year study in a London cohort of homosexual men. Genitourin Med 1990;66:238-43

9 Alcabes P, Munoz A, Vlahov A, Friedland G. Estimation of time from seroconversion to AIDS in HIV-infected intravenous drug users in the US. 8th International Conference on AIDS/3rd STD World Congress, Amsterdam 1992. (Abstract PoC4474, Vol 2).

10 Jordi T, Muga R, Tudela P, et al. AIDS incidence in intravenous drug users from a general hospital of Barcelona. 8th International Conference on AIDS/3rd STD World 8th International Conference on AIDS/3rd STD World
Congress, Amsterdam 1992. (Abstract PuC 8228, Vol 2).

11 Montalla F, Di Sora F, Recchia O, et al. The natural history of the HIV infection in HIV-seropositive intravenous drug users. 7th International Conference on AIDS, Florence 1991. (Abstract W.C.3354, Vol 2).

12 McNeil A, Gore S, Bird A, et al. Progression to AIDS or ARC in the Edinburgh city hospital cohort. 7th International Conference on AIDS, Florence 1991. (Abstract M.C.3142, Vol 1).

13 Selwyn P, Schoenbaum E, Davenny K, Robertson VJ, Feingold AR, et al. Prospective study of human immunodeficiency virus infection and pregnancy outcomes in intravenous drug users. $f A M A$ 1989;261: comes in

14 Lindgren $\dot{S}$, Anzen $B$, Bohlin $A B$, et al. HIV and childbearing: clinical outcome and aspects of mother-tobearing: clinical outcome and aspects of

15 Flanigan T, Jesdale B, Zierler S, et al. Fall in CD4 count among HIV infected women: a comparison of intravenous drug use and-heterosexual transmission groups. 8th International Conference on AIDS/3rd STD World Congress, Amsterdam 1992. (Abstract PoC 4369, Vol 2).

16 Sorice F, Turbessi G, Monacelli M, et al. HIV and women. 8th International Conference on AIDS/3rd STD World Congress, Amsterdam 1992. (Abstract PuC 8241, Vol 2). 